\title{
PREPARATION OF SPERMATOZOA FOR ELECTRON AND LIGHT MICROSCOPY
}

\author{
R. C. JONES* \\ Wellcome Institute of Comparative Physiology, Zoological Society of London, \\ Regent's Park, London NW1 $4 R$ T
}

(Received 11th October 1972)

As a sample of semen contains spermatozoa of various types depending on their normality, stage of maturity and degree of cytolysis, a quantitative study of the structure of the sample must consider the frequency of the different morphological types in a representative sub-sample. The effects of treatments may be determined by comparing different sub-samples. Since the methods that have been described for preparing spermatozoa for electron microscopy (BirchAndersen \& Blom, 1963; Saacke \& Almquist, 1964; Healey, 1969; Quinn, White \& Cleland, 1969) have disadvantages which make them unsuitable for use in such a study, a number of different methods have been examined. The procedures described below were developed for speed and convenience. They have given consistent results when used to prepare samples of spermatozoa from various sources (e.g. epididymis, semen, diluted and stored semen) and from a variety of mammals including the domestic ungulates, carnivores and rodents. For electron microscopy, methods have been developed to sample relatively few spermatozoa, to obtain good fixation and to concentrate, support and orientate them during embedding. Methods of preparing spermatozoa for light microscopy were developed to avoid the necessity of using expensive equipment and to prevent movement of cells during counting and photomicrography.

The composition of the recommended fixatives and washing solutions are: PFG-cacodylate:

$11 \%$ picric acid, $1 \%$ formaldehyde, $1.25 \%$ glutaraldehyde and $150 \mathrm{~mm}$-sodium cacodylate (preparation described by Ito \& Karnovsky, 1968).

Sucrose-cacodylate: $105 \mathrm{~mm}$-sucrose and $150 \mathrm{~mm}$-sodium cacodylate.

Osmium-cacodylate: $40 \mathrm{~mm}$-osmium tetroxide, $75 \mathrm{~mm}$-glucose and $150 \mathrm{~mm}$ sodium cacodylate.

Stock solutions of $25 \%$ glutaraldehyde, $0 \cdot 1 \mathrm{~N}$-hydrochloric acid, $80 \mathrm{~mm}$ osmium tetroxide, $600 \mathrm{~mm}$ sodium cacodylate and $1.5 \mathrm{~m}$-sucrose are used to prepare the fixatives and washes. Sodium cacodylate is adjusted to $\mathrm{pH} 7.3$ by including $10 \mathrm{~mm}$-hydrochloric acid in the solutions. Glutaraldehyde is added within a few hours of use.

For the initial fixation, dilute suspensions were concentrated by centrifugation for $10 \mathrm{~min}$ at $700 \mathrm{~g}$ and the supernatant removed before resuspension. About $10^{8}$ spermatozoa concentrated in $0.2 \mathrm{ml}$ were diluted with $6 \mathrm{ml}$ PFG-

\footnotetext{
* Present address: Department of Biological Sciences, University of Newcastle, N.S.W. 2308, Australia.
} 
cacodylate at the same temperature as the sample $\left(30^{\circ} \mathrm{C}\right)$, and mixed by gentle agitation with a Pasteur pipette. After 20 min fixation, the spermatozoa were recovered by centrifugation and removal of the supernatant. They were then resuspended in sucrose-cacodylate and cooled to $5^{\circ} \mathrm{C}$ for subsequent processing. Samples have been stored satisfactorily at $5^{\circ} \mathrm{C}$ for several days at this stage of preparation. Spermatozoa were osmicated for $30 \mathrm{~min}$ in osmium-cacodylate and re-washed in the cacodylate buffer by the same procedures of concentrating and resuspending that were used for the initial fixation.

Spermatozoa were usually concentrated and supported (Kellenberg, Ryter \& Sechaud, 1958) in agar after osmication but samples supported before osmication were also well preserved. Most of the equipment for the process (Pl. 1, Fig. 2) was prepared from a 1-ml plastic tuberculin syringe (Gillette 'Scimitar', Gillette Surgical, Isleworth, Middlesex) modified by removing the nose and back of the barrel (Pl. 1, Fig. 3) and shortening the piston (Pl. 1, Fig. 4) so that it did not penetrate the full length of the barrel. After lubricating the rubber plunger of the piston with aqueous glycerol and inserting it into the barrel, the suspension of spermatozoa (concentrated by centrifugation into about $0.3 \mathrm{ml}$ ) was pipetted onto the plunger. The syringe was then transferred to a water bath at $60^{\circ} \mathrm{C}$ to warm for $1 \mathrm{~min}$. A solution $(0.05 \mathrm{ml})$ of $2 \%$ agar in sucrose $(300 \mathrm{~mm})$ at $60^{\circ} \mathrm{C}$ was layered under the suspension by carefully injecting it from a $1-\mathrm{ml}$ tuberculin syringe fitted with a blunted stainless-steel needle $(60 \times 1 \mathrm{~mm})$; the container was centrifuged for $15 \mathrm{~min}$ at $1500 \mathrm{~g}$ in a nylon sleeve (Pl. 1, Fig. 1) at $60^{\circ} \mathrm{C}$ and transferred to an ice bath to cool (Pl. 1, Fig. 2 ). By pushing the piston through the barrel with another syringe piston modified by removing the rubber plunger (PI. 1, Fig. 5), the cylinder of agar (Pl. 1, Fig. 7) was removed and dropped into cold 30\% alcohol. As a routine procedure, eight samples at a time are concentrated using an MSE Minor centrifuge (MSE Ltd, Crawley, Sussex) fitted with eight buckets.

\section{EXPLANATION OF PLATE 1}

Frcs 1 to 5. Apparatus for concentrating fixed spermatozoa into agar showing: (Fig. 1) the modified syringe in nylon sleeve ready for centrifugation; (Fig. 2) the syringe after centrifugation showing the agar cylinder (arrows show top and bottom) above the rubber plunger and the suspending medium above the agar; (Fig. 3) barrel of syringe; (Fig. 4) piston of syringe; (Fig. 5) syringe piston with rubber plunger removed.

Fig. 6. Agar cylinder containing $50 \times 10^{6}$ spermatozoa.

Frg. 7. Agar cylinder containing $100 \times 10^{6}$ spermatozoa-the arrow shows the line for sectioning in halves.

FIG. 8. Light micrograph of $2-\mu \mathrm{m}$ araldite section showing the concentration and orientation of spermatozoa. Phase contrast. $\times 437$.

Figs 9 to 11. Sagittal sections of the anterior end of the heads of ram spermatozoa. $\times 41,000$.

FIG. 9. Fixed in PFG-cacodylate.

FIG. 10. Fixed in $4 \%$ formaldehyde-cacodylate.

Fic. 11. Fixed in a combination of glutaraldehyde and osmium tetroxide in sodium cacodylate (Hirsch \& Fedorko, 1968).

Figs 12 to 14 . Photomicrographs of heads of fixed spermatozoa mounted in water on agar smear. Phase contrast. $\times 2280$.

Fig. 12. Spermatozoon from the cuis, Galea musteloides.

FIG. 13. Normal boar spermatozoon.

Fig. 14. Boar spermatozoon showing some swelling of the acrosome. 


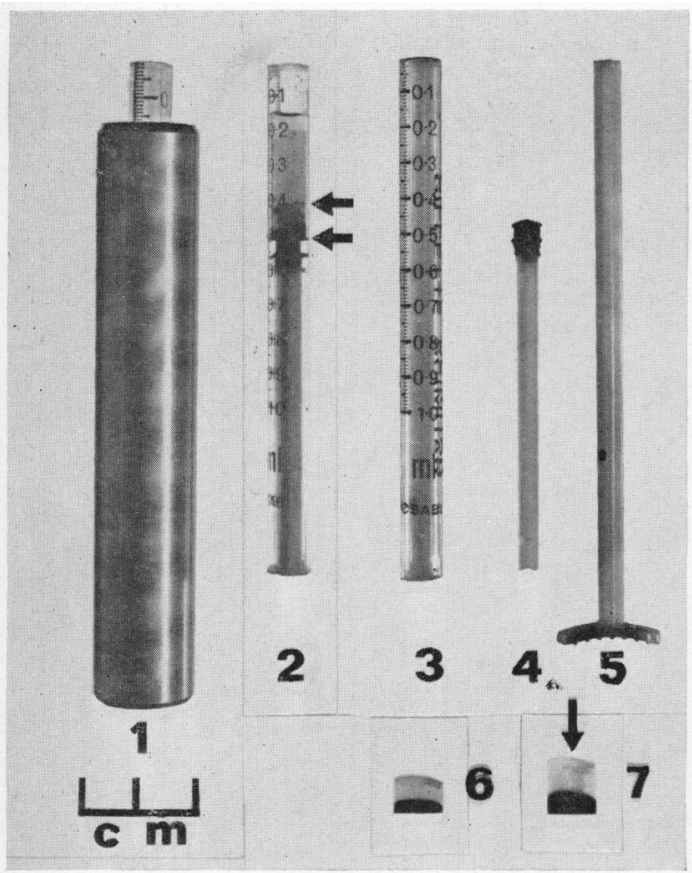

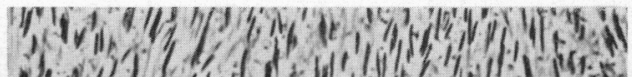

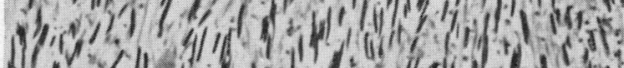

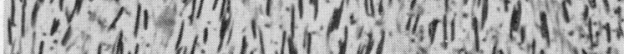

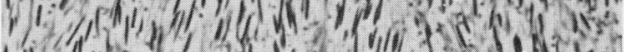

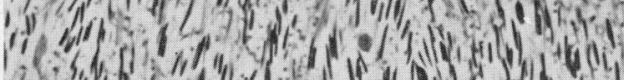

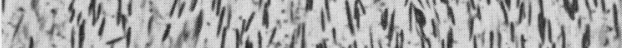

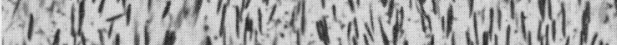

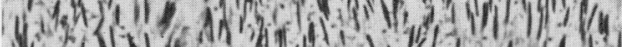

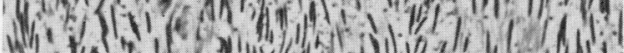

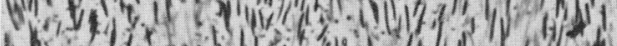

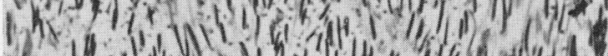

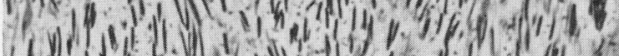

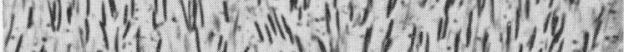
$y$ is

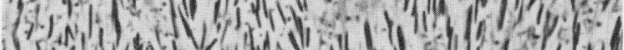

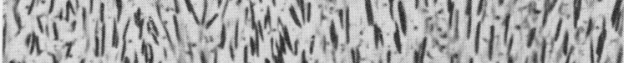

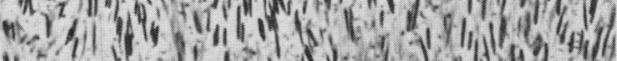
15ivicin

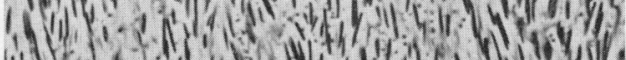
(14) Fa

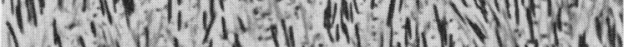

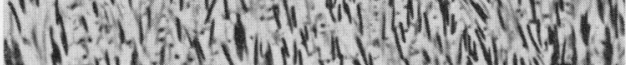

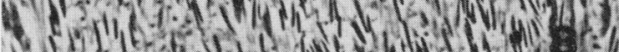

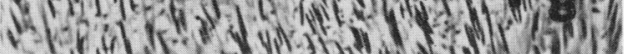

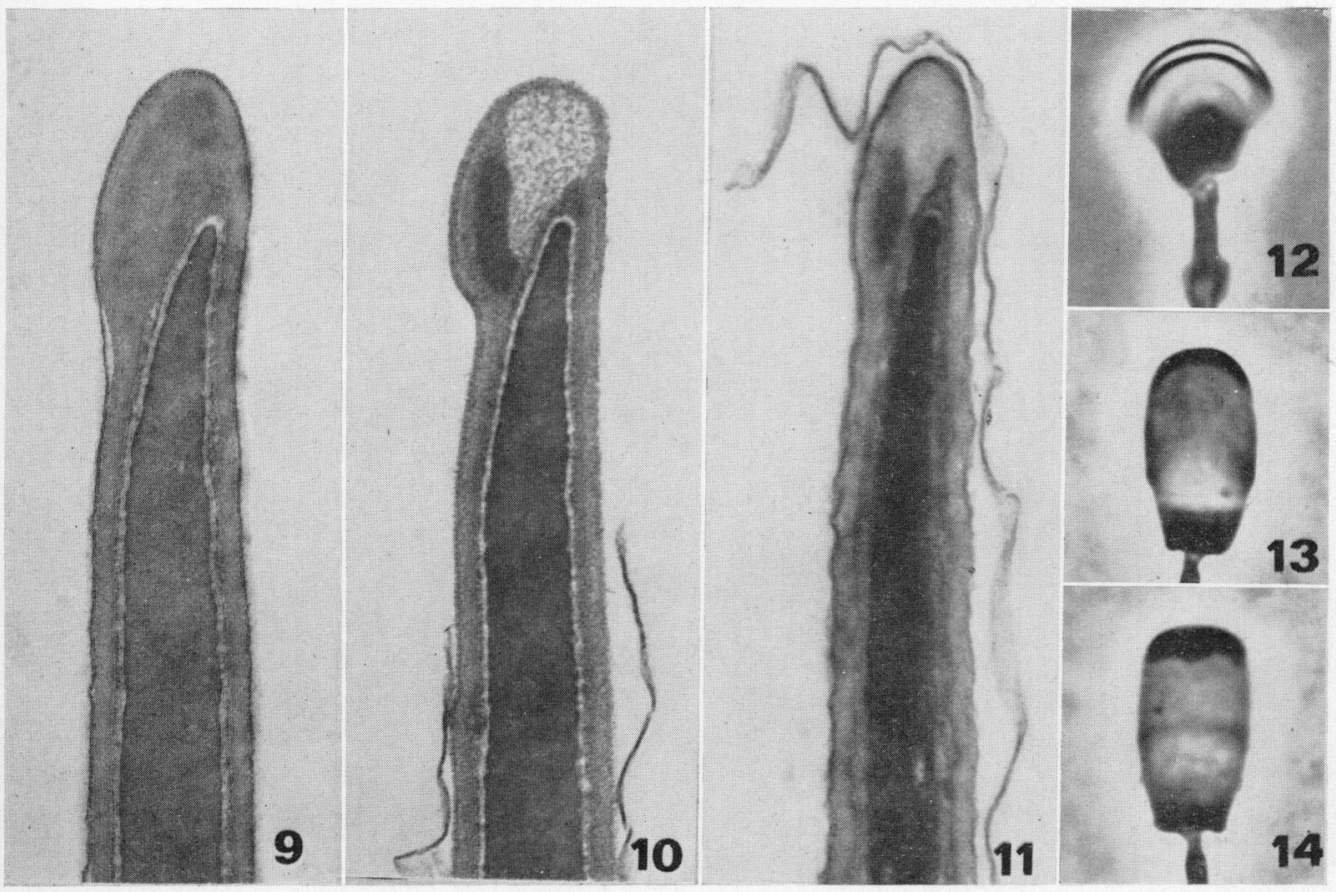


The centrifugation caused most spermatozoa to lie flat on their dorsal or ventral surfaces, forming a dark region at the base of the agar cylinder and leaving a clear region of agar above (Pl. 1, Fig. 7). The cylinder was placed on a dental pad and cut into blocks with a razor blade by first dividing it in halves vertically (Pl. 1, Fig. 7) and laying these with the cut surface downwards. Each half was then divided into three blocks (about $5 \mathrm{~mm}$ long and 1 to $2 \mathrm{~mm}$ wide) by two other cuts along the longitudinal plane, at right angles to the first cut, so that one end was dark (containing spermatozoa) and the other clear (mainly agar). The blocks were then dehydrated and embedded like pieces of tissue and orientated during embedding in Size 3 gelatin capsules (Parke, Davis \& Co., Hounslow) so that the longest edge was horizontal to the bench (i.e. one side was dark and the other clear). Consequently, spermatozoa were sectioned at right angles to the flat plane of the head and the incidence of heads sectioned obliquely was low (Pl. 1, Fig. 8). Samples of less than $10^{8}$ spermatozoa have

Table 1. Comparisons of different initial fixatives for electron microscopy showing their effects on the incidence of intact plasma membranes covering the acrosome of ejaculated ram spermatozoa

\begin{tabular}{|c|c|c|c|c|c|c|}
\hline $\begin{array}{c}\text { Experiment } \\
\text { no. }\end{array}$ & $\begin{array}{l}\text { No. of } \\
\text { replicates }\end{array}$ & $\begin{array}{l}\text { Fixative used } \\
\text { for comparison }\end{array}$ & $\begin{array}{l}\text { Mean } \% \\
\text { intact } \\
\text { membranes }\end{array}$ & $\begin{array}{c}\text { Test } \\
\text { fixalive }\end{array}$ & $\begin{array}{l}\text { Mean } \% \\
\text { intact } \\
\text { membranes }\end{array}$ & $\begin{array}{l}\text { S.E. of } \\
\text { means }\end{array}$ \\
\hline $\begin{array}{l}1 \\
2 \\
2 \\
3 \\
4\end{array}$ & $\begin{array}{l}4 \\
1 \\
1 \\
2 \\
1\end{array}$ & $\begin{array}{l}1 \% \text { glutaraldehyde } \\
1 \% \text { glutaraldehyde } \\
1 \% \text { glutaraldehyde } \\
1 \% \text { glutaraldehyde } \\
\text { PFG }\end{array}$ & $\begin{array}{l}63 \\
52 \\
52 \\
69 \\
85\end{array}$ & 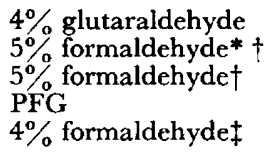 & $\begin{array}{l}69 \\
15 \\
17 \\
84 \\
34\end{array}$ & $\frac{1.0}{-\frac{1.5}{-}}$ \\
\hline
\end{tabular}

* This fixative was the phosphate-buffered neutral formalin described by Hancock \& Shaw (1955); the other fixatives were buffered with 150 mM-sodium cacodylate $(\mathrm{pH} 7 \cdot 3)$.

$\dagger$ Prepared from $40 \%$ commercial formalin.

$\ddagger$ Prepared by depolymerization of paraformaldehyde (Pease, 1964).

been prepared using these methods (Pl. 1, Fig. 6) but as this often resulted in a reduced density of cells, it is recommended that a narrower barrel and piston be manufactured for this purpose.

A number of fixatives other than PFG-cacodylate were tested for the initial fixation and some of the results are summarized in Pl, 1, Figs 9 to 11, and Table 1 in which the incidence of breakages of the plasma membrane over the acrosome is used as a measure of response (Jones, 1971a) for comparing the suitability of the fixatives. Direct fixation in either osmium tetroxide or a mixture of osmium tetroxide and glutaraldehyde (Hirsch \& Fedorko, 1968) caused considerable breakage of the plasma membrane, structural alteration of the acrosome and some damage to the sperm mitochondria (e.g. compare Pl. 1, Fig. 9 with the Plates shown by Healey (1969) or Quinn et al. (1969) for the effects of osmium fixation, and Pl. 1, Fig. 9 with Pl. 1, Fig. 11 for the effects of using osmium and glutaraldehyde together). The acrosomes of spermatozoa fixed in formaldehyde showed uneven electron density for the three ejaculates tested; for one of the replicates (Exp. 4), the acrosome was also granular (Pl. 1, Fig. 10). The incidence of plasma membrane breakages around the head (Table 1) and tail was also high and the structure of the mitochondria was poorly preserved. 
Glutaraldehyde was the best fixative when used alone; although not statistically significant, a concentration of $4 \%$ was consistently better than one of $1 \%$ (Table 1). However, PFG gave marginally better preservation than glutaraldehyde (Table 1). The effect of varying the concentration of buffer in fixatives has already been described (Jones, $1971 \mathrm{a}, \mathrm{b}$ ).

After the initial fixation, sub-samples of spermatozoa for light microscopy may be stored for months in sucrose-cacodylate in stoppered tubes at $5^{\circ} \mathrm{C}$. The suspensions were smeared on to agar-coated microscope slides (Bishop, Campbell, Hancock \& Walton, 1954), dried and mounted in distilled water under a coverslip. Spermatozoa prepared in this way (Pl. 1, Figs 12 to 14) show as much structural detail when examined by phase contrast microscopy as was shown by Saacke \& Marshall (1968), who examined unfixed spermatozoa using Normarski differential interference microscopy; phase contrast is favoured for photomicrography because it has the greater depth of focus.

A number of experiments using essentially the same methods as those described in this paper have already been published (Jones, 1971a, b). Counts of the incidence of different morphological types of spermatozoa in low-power electron micrographs have been used as the measure of response in these experiments and replication of the design with different ejaculates has shown that the treatments consistently rank in the same order. The estimates of experimental error in the analyses of variance were usually larger than expected from statistical theory. The amount of inflation was about the same as that usually obtained by this author for counts of unstained spermatozoa in eosinnigrosin smears.

The assistance of Mrs P. A. Gallant and Mr T. Dennett are gratefully acknowledged. The work was supported by grants from the Wellcome Trust, the Meat and Livestock Commission and Unilever Ltd. The author was supported by a Ford Foundation Fellowship.

\section{REFERENCES}

Birch-Andersen, A. \& Blom, E. (1963) Concentrating ejaculated spermatozoa for electron microscopy. Nature, Lond. 199, 201.

Bishop, M. W. H., Gampbell, R. G., Hancock, J. L. \& Walton, A. (1954) Semen characteristics and fertility in the bull. $\mathcal{7}$. agric. Sci., Camb. 44, 227.

Hancock, J. L. \& Shaw, I. G. (1955) A new difference between live and dead spermatozoa. Nature, Lond. 176, 260.

Healey, P. (1969) The effect of freezing on the ultrastructure of the spermatozoon of some domestic animals. 7. Reprod. Fert. 18, $2 \mathrm{I}$.

HiRsCH, J. G. \& FEDORKo, M. E. (1968) Ultrastructure of human leukocytes after simultaneous fixation with glutaraldehyde and osmium tetroxide and "postfixation" in uranyl acetate. J. Cell Biol. 38, 615.

Ito, S. \& Karnorsky, M. J. (1968) Formaldehyde fixatives containing trinitro compounds. F. Cell Biol. 39, $168 \mathrm{~A}$.

JoNEs, R. C. (1971a) Ultrastructure of mammalian spermatozoa: the effects of buffer concentration in fixatives for boar spermatozoa. Micron, 2, 350 .

Jones, R. C. (197lb) Studies of the structure of the head of boar spermatozoa from the epididymis. 7 . Reprod. Fert. Suppl. 13, 51.

Kellenberc, E., Ryter, A. \& Sechaud, J. (1958) Electron microscopic study of DNA-containing plasma. II. Vegetative and phage DNA as compared with normal bacterial nucleoids in different physiological states. 7. biophys. biochem. Cytol. 4, 671 . 
Pease, D. G. (1964) Histological techniques for electron microscopy, 2nd edn, p. 53. Academic Press, New York and London.

Quinn, P. J., White, I. G. \& Gleland, K. W. (1969) Chemical and ultrastructural changes in ram spermatozoa after washing, cold shock and freezing. F. Reprod. Fert. 18, 209.

SAACKe, R. G. \& Almquist, J. O. (1964) The ultrastructure of bovine spermatozoa. I. The head of normal ejaculated sperm. Am. F. Anat. 115, 143.

SaAcke, R. G. \& Marshall, G. E. (1968) Observations on the acrosomal cap of fixed and unfixed bovine spermatozoa. F. Reprod. Fert. 16, 511. 